Abstracta Iranica Abstracta Iranica

Revue bibliographique pour le domaine irano-aryen

Volume 31 | 2011

Comptes rendus des publications de 2008

\title{
The Royal Hunt in Eurasian History. Philadelphia, University of Pennsylvania Press, 2006, 406 p.
}

\section{Denise Aigle}

\section{(2) OpenEdition}

1 Journals

Édition électronique

URL : http://journals.openedition.org/abstractairanica/39284

DOI : 10.4000/abstractairanica.39284

ISSN : 1961-960X

\section{Éditeur :}

CNRS (UMR 7528 Mondes iraniens et indiens), Éditions de l'IFRI

\section{Édition imprimée}

Date de publication : 15 mai 2011

ISSN : 0240-8910

\section{Référence électronique}

Denise Aigle, «The Royal Hunt in Eurasian History. Philadelphia, University of Pennsylvania Press, 2006, 406 p. », Abstracta Iranica [En ligne], Volume 31 | 2011, document 123, mis en ligne le 11 octobre 2012, consulté le 04 octobre 2020. URL : http://journals.openedition.org/abstractairanica/39284; DOI : https://doi.org/10.4000/abstractairanica.39284

Ce document a été généré automatiquement le 4 octobre 2020.

Tous droits réservés 


\title{
The Royal Hunt in Eurasian History. Philadelphia, University of Pennsylvania Press, 2006, 406 p.
}

\author{
Denise Aigle
}

1 L'ouvrage de T. Allsen, éminent spécialiste de l'Empire mongol, auquel il a déjà consacré de nombreux ouvrages et articles, est une étude magistralement menée sur la chasse royale reposant sur un nombre considérable de sources diverses (textuelles, archéologiques et iconographiques). En treize chapitres, il aborde le thème de la chasse royale sous plusieurs angles dont les principaux sont d'ordre historique, politique et culturel. Cependant, il ne se contente pas d'étudier cette thématique à l'époque mongole, bien que ce soit le point d'ancrage de son ouvrage. Il inscrit ses recherches sur une vaste aire géographique: l'Eurasie dans son ensemble et en donnant de la profondeur historique à son étude puisqu'il prend ses premiers exemples dans l'Antiquité (Égypte, Grèce, Rome, Iran préislamique) poursuivant l'investigation jusqu'à l'Iran qajar inclus.

2 Allsen montre que la chasse royale avait plusieurs fonctions, outre son rôle alimentaire, elle avait également d'autres objectifs. Tout d'abord, elle représentait un modèle pour l'entraînement militaire, et cette fonction est particulièrement valable pour les sociétés steppiques, bien plus que dans l'Europe médiévale, par exemple. La chasse royale avait également une vocation en matière de diplomatie. Les treize chapitres qui constituent l'ouvrage couvrent de nombreuses thématiques dont nous ne pouvons rendre compte dans le cadre d'un abstract, tant est riche la matière de ce livre.

Dans le chapitre 3 «Parks» (p. 34-51), l'A. commence par donner une définition du terme "paradis» (p. 34) dont les attestations remontent à l'Antiquité, par exemple dans la littérature grecque (paradesios) terme qui a pour origine le mot du vieux perse achéménide (paradaida). Xénophon écrit que Cyrus « avait un palais et un grand parc rempli d'animaux » (p. 55). L'A. constate que les souverains musulmans en Inde, en Iran et en Asie centrale poursuivirent cette coutume de doter leurs domaines de parcs avec des animaux (p. 39). L'A. s'intéresse ensuite à ce type de lieu, plus à l'Est, en Chine et 
chez les Mongols. Le chapitre 4 «Partners" (p. 52-82) est également très riche en informations. Il montre bien comment certains animaux pouvaient servir d'auxiliaires aux chasseurs, ceci depuis l'Antiquité, en particulier les faucons (p. 52). Parmi les "animaux chasseurs", il cite les chiens, utilisés également par certains souverains musulmans. S'appuyant sur le témoignage de Marco Polo, il écrit que Qubilai chassait avec de grands aigles. Les félins étaient également très prisés, en particulier le guépard. Dans le chapitre 11 "Intimidation» (p. 207-232), l'A. s'intéresse à la chasse royale conçue comme un stratagème en temps de guerre: les Achéménides utilisaient des chasseurs individuels pour effectuer des opérations d'espionnage. On trouve d'autres exemples (p. 223-224), en relation avec la fonction diplomatique de la chasse. Allsen montre très bien que la chasse royale était non seulement une démonstration de pouvoir, mais qu'elle avait aussi une fonction logistique : «la capacité à projeter le pouvoir à distance» (p. 226). Enfin, dans le chapitre 12 "Internationalization» (p. 233-264) on trouvera d'intéressants développements sur les trafics et échanges d'animaux chasseurs et par conséquent de dresseurs d'animaux (p. 260-264). Allsen démontre que la chasse royale donna naissance à une élite ayant une véritable culture de la chasse : les échanges de cadeaux entre souverains incluaient non seulement des animaux (guépards, faucons, chiens, etc.), mais également des dresseurs d'animaux.

4 Cet ouvrage est un monument en matière de chasse royale sur une longue période et sur une vaste aire géographique qui donne lieu à des comparaisons entre différentes aires culturelles sur une très longue durée. Cette recherche repose sur un impressionnant corpus de sources primaires en de nombreuses langues connues de l'auteur (chinois, persan, russe) ou traduites (329-352) et d'études (p. 353-393). Nul doute que ce livre marque une date dans l'histoire de la chasse royale et restera longtemps un modèle de référence.

INDEX

Thèmes : 4.1. Histoire médiévale

\section{AUTEURS}

DENISE AIGLE

EPHE - Paris 